\title{
Espécies de Uromyces em Leguminosas do Cerrado com Descrição de $U$. galactiae sp. nov.
}

\author{
Denise V. Rezende ${ }^{1} \&$ José C. Dianese ${ }^{1}$ \\ ${ }^{1}$ Departamento de Fitopatologia, Instituto de Ciências Biológicas, Universidade de Brasília, CEP 70919-900, Brasília, DF, Brasil, \\ e-mail: santiago@unb.br
}

(Aceito para publicação em 06/05/2003)

Autor para correspondência: Denise Vilela de Rezende Santiago

REZENDE, D.V. \& DIANESE, J.C. Espécies de Uromyces em leguminosas do Cerrado com descrição de U. galactiae sp. Nov. Fitopatolgia Brasileira 28:495-501. 2003.

\section{RESUMO}

Foram estudadas cinco espécies de Uromyces sobre Bauhinia spp. e uma espécie nova em Galactia peduncularis. Uromyces bauhiniae foi encontrada pela primeira vez sobre B. holophylla, onde somente Uromyces floralis havia sido descrita. Uromyces floralis foi estudada sobre $B$. curvula, hospedeiro inédito no Brasil para esta espécie. Uromyces foveolatus, comum em B. acuruana var. nitida, no cerrado do Mato Grosso e U. goyazensis sobre B. dumosa var. viscidula foram encontradas somente na fase telial em todas as exsicatas examinadas. Uromyces viegasii foi estudada em B. forficata. Uromyces galactiae sp. nov. é o primeiro fungo fitopatogênico associado ao gênero Galactia.

Palavras-chave adicionais: ferrugens neotropicais, taxonomia.

\begin{abstract}
Uromyces species on leguminous hosts from the Cerrado with description of $U$. galactiae sp. nov.

Five Uromyces species were studied on Bauhinia spp. and a new species was described on Galactia peduncularis. Uromyces bauhiniae was found for the first time on Bauhinia holophyla, where only $U$. floralis had been previously described. Uromyces floralis

was studied on B. curvula, inedited host in Brazil for that species. Uromyces foveolatus common in B. acuruana var. nitida in the Cerrado of Mato Grosso and $U$. goyazensis on B. dumosa var. viscidula were both found only in their teleomorphic phase in all exsicates examined. Uromyces viegasii was studied on B.forficata. Uromyces galactiaesp. nov. is the first plant pathogenic fungus found on the Galactia genus.
\end{abstract}

\section{INTRODUÇÃO}

Existem registros de 82 espécies de Uromyces no Brasil (Hennen et al., 1982), sendo que destas, 20 foram encontradas em áreas de cerrado.

Neste estudo foram identificadas e descritas as espécies de Uromyces cujas exsicatas estão depositadas na Coleção Micológica de Referência da Universidade de Brasília (CMRUnB), seguindo a maioria dos critérios taxonômicos adotados por Almeida (1975). Além disso, detalhes morfológicos observados em microscópio ótico e microscópio eletrônico de varredura (MEV) foram acrescentados. As ilustrações ao MEV, permitiram visualizar detalhes das paredes de teliósporos, mostrando retículos presentes os quais formam alvéolos comuns a muitas espécies de Uromyces. No entanto, as dimensões e profundidade dos alvéolos ou depressões que ornamentam as paredes dos teliósporos foram importantes na caracterização de algumas espécies de Uromyces do cerrado.

O presente trabalho visou aprofundar o conhecimento do gênero Uromyces no Cerrado, através de uma descrição ilustrada do grupo de espécies mais disseminadas na região.

As espécies de Uromyces estudadas e fotografadas em MEV apresentaram teliósporos lisos ou reticulados diferindo de Almeida (1975) que encontrou teliósporos lisos, rugosos, levemente reticulados e reticulados. As descrições que seguem não mostraram teliósporos rugosos em material do Cerrado.

Finalmente, seis espécies de Uromyces sobre oito gêneros de Leguminosae, são ilustradas e descritas, mostrando detalhes da diversidade de espécies encontrada no bioma Cerrado.

\section{MATERIAL E MÉTODOS}

Os espécimes estudados pertencem à Coleção Micológica de Referência da Universidade de Brasília (CMRUnB) e são provenientes de áreas de Cerrado do Distrito Federal, Mato Grosso, Mato Grosso do Sul, Maranhão, Minas Gerais, Bahia, Espirito Santo e São Paulo. Taxonomistas dos herbários do Departamento de Botânica da Universidade de Brasília e da Reserva Biológica do IBGE assistiram os autores na identificação das plantas hospedeiras.

Amostras das exsicatas rehidratadas foram cortadas em micrótomo de congelamento, marca Micron HM505E, temperatura de -20 a $-21{ }^{\circ} \mathrm{C}$, seguindo-se a montagem semipermanente em lâminas que foram coradas com lactofenol/ azul de algodão e observadas em microscópio ótico (MO). Solução aquosa de cloral hidratado foi usada quando se pretendia ver os poros germinativos dos esporos. Para a 
observação de detalhes morfológicos ou ontogênicos dos esporos, utilizou-se também o corante de Bruzesse \& Hassan (1983) sem fenol, ou seja, com a seguinte composição: $40 \mathrm{~g}$ de cloral hidratado, $15 \mathrm{ml}$ de clorofórmio, $125 \mathrm{ml}$ de ácido láctico a $90 \%, 300 \mathrm{ml}$ de etanol $95 \%$ e $0,6 \mathrm{~g}$ de azul de anilina. Em seguida, as lâminas foram seladas com esmalte de unha, etiquetadas e armazenadas para estudo. As observações e fotografias foram feitas em fotomicroscópio Zeiss-Axiophot E (Carl Zeiss Oberkuchen, Alemanha).

Para o exame microscópico da superfície das estruturas fúngicas usou-se o MEV. Fragmentos frescos ou hidratados de tecidos medindo $0,5 \times 0,8 \mathrm{~cm}$, posteriormente foram colocados em recipientes com solução fixadora de glutaraldeído a $3 \%$ em tampão cacodilato de sódio $0,05 \mathrm{M}, \mathrm{pH}$ 6,9. Os recipientes foram tampados e deixados em geladeira a $4{ }^{\circ} \mathrm{C}$ por $12 \mathrm{~h}$. Em seguida, efetuaram-se cinco lavagens sucessivas do material com a mesma solução tampão. Após a lavagem as peças foram tratadas com tetróxido de ósmio $\left(\mathrm{OsO}_{4}\right)$ a $1 \%$ no mesmo tampão de cacodilato permanecendo em refrigerador a $4{ }^{\circ} \mathrm{C}$ por $4 \mathrm{~h}$. Posteriormente, nova série de cinco lavagens consecutivas foi feita com a solução tampão.

O material foi desidratado em uma série aquosa contendo $30 \%, 50 \%, 70 \%, 85 \%, 95 \%$ e $100 \%$ de acetona. Os fragmentos permaneceram em cada concentração por 10 a 20 min, sendo que a última solução foi trocada três vezes. Em seguida, foi feita a secagem do material ao ponto crítico em um aparelho de secagem CPD-030 Balzers (Baltec, Fuerstentum, Liechtenstein) utilizando-se $\mathrm{CO}_{2}$ líquido. Os fragmentos de tecidos secos foram colados sobre suportes metálicos pincelados nas bordas com pasta condutiva de prata. Os suportes contendo o material foram então cobertos com ouro por meio de pulverização catódica em aparelho marca Balzers, modelo SCD50 por $140 \mathrm{~s}$. Observações e microfotografias foram feitas em MEV marca Jeol, modelo JSM840-A (Jeol Ltd, Tóquio, Japão) com acelerações de 5 e $10 \mathrm{KV}$ e distância de trabalho de $20 \mathrm{~mm}$. A base para identificação das espécies incluiu estudos de espessura da parede, ornamentação, cor, tamanho e forma dos teliósporos e urediniósporos, características dos pedicelos dos teliósporos e o número e posição dos poros germinativos em urediniósporos. Ademais, a presença ou ausência e forma das paráfises, formas dos esporos e sintomas ou sinais no hospedeiro, foram características adicionais que também ajudaram na identificação das espécies.

\section{RESULTADOS E DISCUSSÃO}

As espécies de Uromyces estudadas foram identificadas e, descritas a seguir:

1 - Uromyces bauhiniae P. Henn. In: Hedwigia 34:90. 1895. Sinonímias: Uromyces praetextus Vest. Ark. Bot.4:19. 1905; Uromyces guatemalensis Vest. Ark. Bot.4:20. 1905.

Espermogônios e écios não-conhecidos. Urédios constituídos de soros mistos formando urediniósporos e teliósporos, anfígenos, maioria hipófilo, (0,7-) 1,0 (-1,7) x $(0,6-$ ) $0,8(-1,0) \mathrm{mm}$, marrom-canela (Figura 1- A). Urediniósporos
(20-) 26 (-31) x (18-) 22 (-25) $\mu \mathrm{m}$, geralmente elipsóides ou obovóides, parede 1,5 - $2 \mu \mathrm{m}$ de espessura, marrom-dourados, pedicelados, equinulados, papilados, poros germinativos equatoriais conspícuos ou espalhados pelos esporos, três seis, em geral quatro (Figura 1- B; Figura 2- B e C). Télios às vezes mistos, marrons-chocolate, irrompentes, pulverulentos (Figura 2- A). Teliósporos pedicelados, unicelulares, elipsóides a obovóides, (22-) 27 (-30) x (18-) 21 (-25) $\mu \mathrm{m}$, reticulados, alveolados; paredes bilaminadas, 2 - 2,5 $\mu$ m de espessura e 6 $\mu \mathrm{m}$ na papila; alvéolos medindo 0,6 - 1,5 $\mu \mathrm{m}$ de diâmetro (Figura 1 - C, D; Figura 2 - D, E - F). Pedicelos hialinos, longos, 40 - 50 $\mu \mathrm{m}$ de comprimento, descíduos, quebrando próximos às bases dos esporos.

Espécimes examinados: em folhas vivas de Bauhinia holophylla (Bong.) Steud. Bairro Granada, Uberlândia, MG, 22 dez. 1992, leg. C. Furlanetto 94, UB (col. micol.) 2928; Divinópolis, MG, 01 Jan. 1993, leg. J.C. Dianese 1566, UB (col. micol.) 5774; loteamento em frente à Feira Agropecuária de Divinópolis, MG, 26 jun. 1995, leg. C.A. Inácio 329, UB (col. micol.) 9010. Em folhas vivas de B. bongardii Steud. Estação Ecológica das Águas Emendadas, a $17 \mathrm{~km}$ da sede Administrativa, Planaltina, DF, 23 jul. 1997, leg. M. Sanchez 2870, UB (col. micol.) 15053.

Almeida (1975) estudou espécies de Uromyces parasitas de Bauhinia sp.provenientes principalmente de Mato Grosso, Goiás e Minas Gerais. Uromyces bauhinia foi encontrada sobre Bauhinia bongardii Steud., B. cuiabensis Steud., B. hiemalis Malme. e Bauhinia sp. Neste estudo, U. bauhiniae está presente em B. bongardii e B. holophylla. Entretanto, cabe lembrar que $B$. holophylla foi citada como hospedeiro de Uroymces floralis Vest. Os resultados mostraram que não se trata de $U$. floralis, pois a espécie aqui identificada não apresenta télios ocorrendo em flores, caules e folíolos, além disso, sempre causando hipertrofia e formando espermogônios

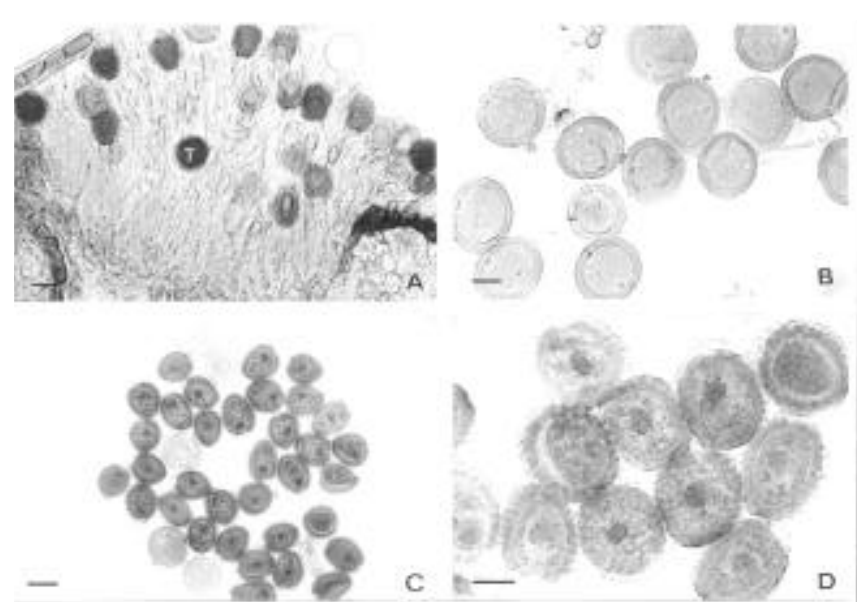

FIG. 1 - Uromyces bauhiniae sobre Bauhinia holophylla. A - Corte de soro misto contendo urediniósporos e teliósporos (T) vistos ao MO. B - Urediniósporos obovóides a globóides vistos ao MO, mostrando paredes espessas e poros germinativos supraequatoriais. C e D Teliósporos ao $\mathrm{MO}$ com paredes reticuladas e alveoladas, levemente papilados. Barras: A e C $=20 \mu \mathrm{m}$; B e D $=10 \mu \mathrm{m}$. 
Espécies de Uromyces em leguminosas do cerrado com descrição...
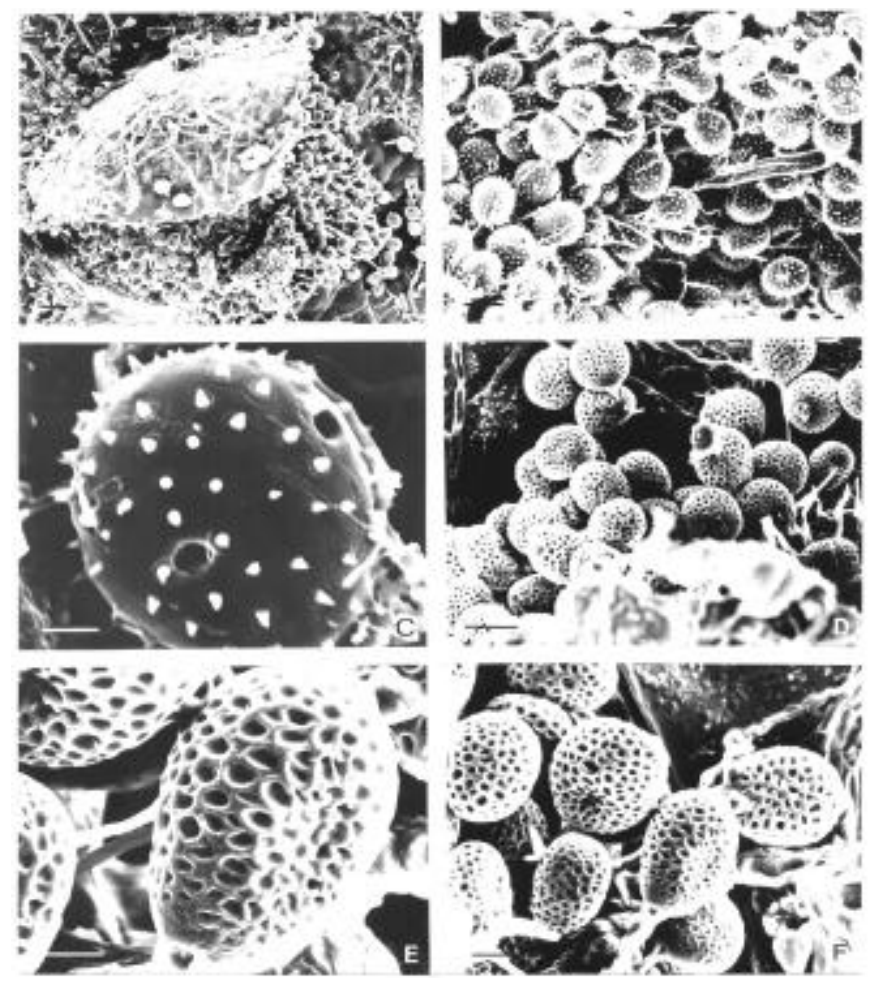

FIG. 2 - Uromyces bauhiniae sobre Bauhinia holophylla. A. Soro subepidérmico irrompente, contendo teliósporos e urediniósporos vistos ao MEV. B - Grupo de urediniósporos equinulados vistos ao MEV. C - Detalhe de urediniósporo equinulado com halos na base das equinulações e dois poros germinativos. D, E e F - Teliósporos reticulados ao MEV mostrando alvéolos profundos de 0,6 - 2,5 $\mu \mathrm{m}$ de diâmetro. Barras: $\mathrm{A}=40 \mu \mathrm{m} ; \mathrm{B}$ e $\mathrm{D}=20 \mu \mathrm{m} ; \mathrm{C} \mathrm{e} \mathrm{E}=5 \mu \mathrm{m} ; \mathrm{F}=10 \mu \mathrm{m}$.

epífilos.

Além disso, os teliósporos de U. floralis (17 - 27 x 15 $20 \mu \mathrm{m}$ ) são menores do que os de $U$. bauhiniae (20-30 x $18-27$ $\mu \mathrm{m})$, sendo elipsóides, com alvéolos, medindo 1,0 - 1,5 $\mu \mathrm{m}$ e com papilas de até $2 \mu \mathrm{m}$ de espessura. Já, $U$. bauhiniae apresenta teliósporos principalmente obovóides, alvéolos menores $(0,6-1,5 \mu \mathrm{m})$ e papilas de até $6 \mu \mathrm{m}$. Portanto, no presente caso, em nove coletas de $B$. holophylla e duas de $B$. bongardii, presentes no Cerrado, verificou-se que em todas as exsicatas examinadas apenas $U$. bauhiniae estava presente, não sendo observada nenhuma ocorrência de $U$. floralis.

2. Uromyces floralis Vest. In: Ark. Bot. 4:23. 1905.

Sinonímia: Uromyces verus Jacks. \& Holw. Mycologia 32:344. 1931.

Urédios e écios não-vistos. Espermogônios, grupo V, tipo 4 , medindo $64 \mu \mathrm{m}$ na base, $48 \mu \mathrm{m}$ no topo, e $84 \mu \mathrm{m}$ de profundidade, epífilos, raros, próximos de télios (Figura 3 - A). Télios anfígenos, (1-) 2 (-3) x (0,8-) 1 (-2) mm, ocorrendo nas flores, vagens, caules e folíolos, marrom-dourados, dispersos ou em grupos pequenos, subepidérmicos, tornando-se irrompentes com volumosa produção de teliósporos (Figura 3 - B e D). Teliósporos pedicelados, unicelulares, obovóides, globóides ou elipsóides (19-) 22 (-24) x (17-) 20 (-22) $\mu \mathrm{m}$; paredes laterais (1,5-) $2(-2,5) \mu \mathrm{m}$ de espessura, reticuladas irregularmente, alvéolos com 1 - 1,5 $\mu \mathrm{m}$ de diâmetro, levemente espessados nos ápices, formando uma papila pouco proeminente com 2 - 2,5 $\mu$ m de altura (Figura 3 -C e E). Pedicelos (48-) 62 (-80) $\mu \mathrm{m}$ de comprimento, hialinos, simples, que se quebram próximo à base do teliósporo.

Espécimes examinados: em folhas vivas de Bauhinia curvula Benth.: Fazenda Nova Índia, Cristalina, GO, 10 abr. 1993, leg. J.C. Dianese 829, UB (col. micol.) 4477; estrada BR050 entre Catalão e Pires Belo, GO, 25 mar. 1993, leg. M. Sanchez 54, UB (col. micol.) 3644; Fazenda Pedra Grande, Buritis, MG, 8 maio 1993, leg. J.C. Dianese 904, UB (col. micol.) 4558.

As dimensões das estruturas e esporos e demais características morfológicas da espécie estudada, confirmam o relato de Almeida (1975) para U. floralis. Das espécies descritas em Bauhinia sp.: U. goyazensis P. Henn. (Hennings, 1895), U. anthemophilus Vest. (Vestergren, 1905) e U. viegasii Almeida (Almeida, 1975) não possuem écios, urédios e espermogônios conhecidos. Uromyces goyazensis caracterizase por apresentar teliósporos de até $10 \mu \mathrm{m}$ de comprimento, portanto maiores que os de $U$. floralis e retículos formando alvéolos rasos, muito pequenos, 0,5-1 $1 \mu \mathrm{m}$, parecendo
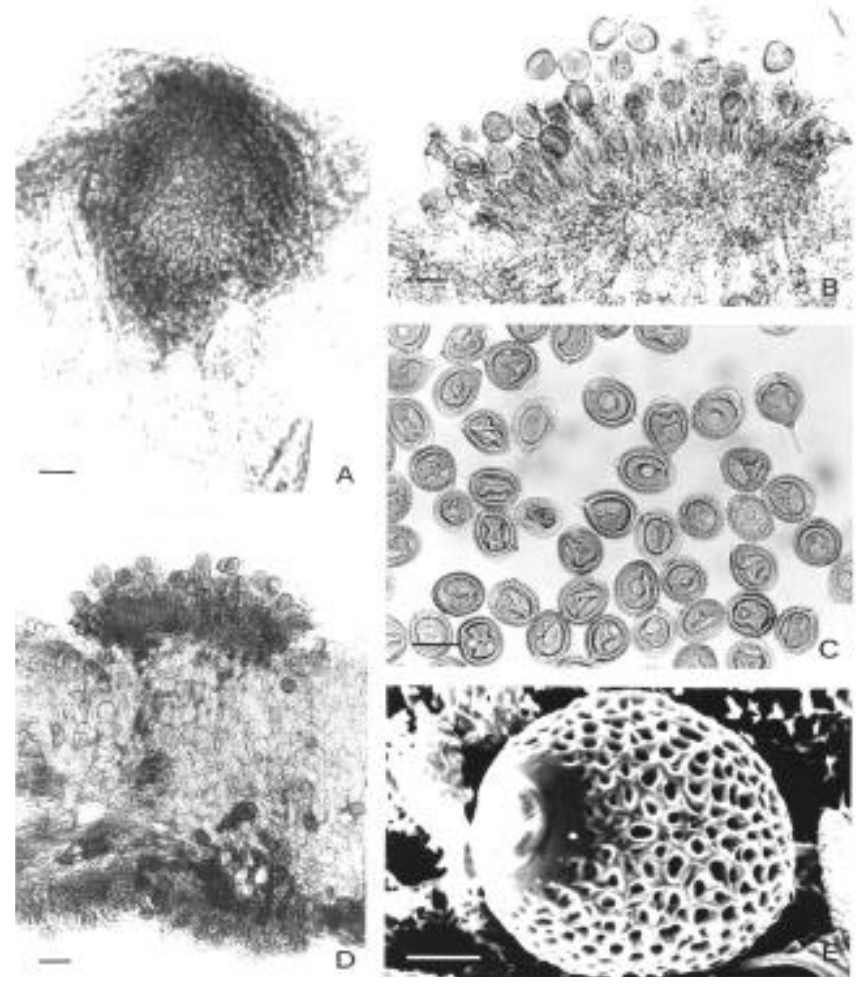

FIG. 3 - Uromyces floralis sobre órgãos florais de Bauhinia curvula. A - Corte de espermogônio epífilo em pétalas, visto ao MO. B - Corte de télio anfígeno visto ao MO. C - Teliósporos reticulados, com papilas evidentes e paredes bilaminadas, alveolados quando vistos ao MO. D - Caráter anfígeno dos télios ao MO. E - Teliósporo reticulado com alvéolos irregulares de $1-1,5 \mu \mathrm{m}$ de diâmetro, vistos ao MEV. Barras: $\mathrm{A}=10 \mu \mathrm{m} ; \mathrm{B}$ e $\mathrm{C}=20 \mu \mathrm{m} ; \mathrm{D}=30 \mu \mathrm{m} ; \mathrm{E}=5 \mu \mathrm{m}$. 
verrugosos ao microscópio ótico. Já $U$. anthemophilus é muito próximo de U.floralis (Vestergreen, 1905, Almeida, (1975), mas difere por apresentar retículos de 2 - 2,5 $\mu$ m de diâmetro, paredes espessas, 3 - 3,5 $\mu \mathrm{m}$, além da ausência de uma papila no ápice do teliósporo. Uromyces viegasii é uma espécie próxima de $U$. floralis e $U$. anthemophilus, mas difere por formar retículos salientes, portanto alvéolos profundos nas paredes enquanto que $U$. anthemophilus apresenta paredes finas em teliósporos papilados. Além disso, as lesões de $U$. anthemophilus nos folíolos são rodeadas por halos amarelos. (Almeida, 1975). Esses sintomas estão ausentes em todas as outras espécies de Uromyces em Bauhinia sp. Portanto, U. floralis é a espécie detectada agora em $B$. curvula no Cerrado e registrada no Brasil pela primeira vez.

3. Uromyces foveolatus Juel. In: Bih. Tillk. Svenska Vet. Akad. Handl. 23:16. 1897.

Espermogônios e écios não-vistos. Urédios mistos 0,1 - 0,7 mm de diâmetro, anfígenos, aparafisados, a maioria hipófila, subepidérmicos na origem, irrompentes, marrons, pulverulentos (Figura 4 - A, B e C). Urediniósporos globóides, obovóides a elipsóides (26-) 30 (-32) x (25-) 27 (-28) $\mu \mathrm{m}$, equinulados; parede, 2 - $3 \mu \mathrm{m}$ de espessura, quatro poros germinativos equatoriais, unizonados, com capas hialinas sobre os poros (Figura 4 - D; Figura 5 - C). Télios marrom-escuros a pretos, mistos (Figura 5 - A). Teliósporos pedicelados, papilados, globóides a elipsóides, unicelulares, (25-) 29 (-30) x (21-) 24 (-26) $\mu$ m; parede escura, bilaminada; parede interna $1-1,5 \mu \mathrm{m}$ de espessura e parede externa 1,5 - $2 \mu \mathrm{m}$ de espessura, reticulada, alvéolos 2 2,5 $\mu \mathrm{m}$ de diâmetro; papilas 5 - $7 \mu \mathrm{m}$ de espessura; pedicelos hialinos, até $25 \mu \mathrm{m}$ de comprimento e com a base rugosa (Figura
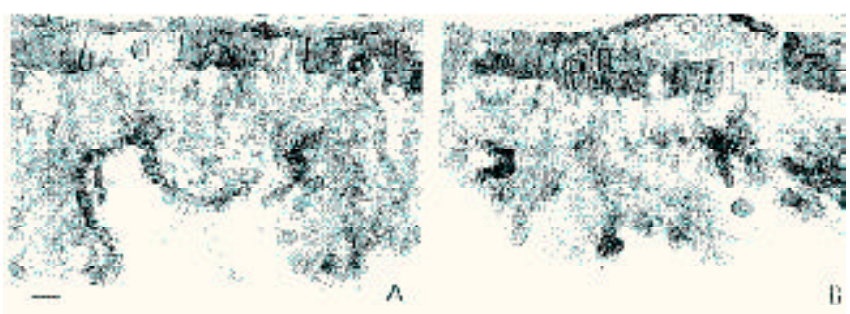

b)
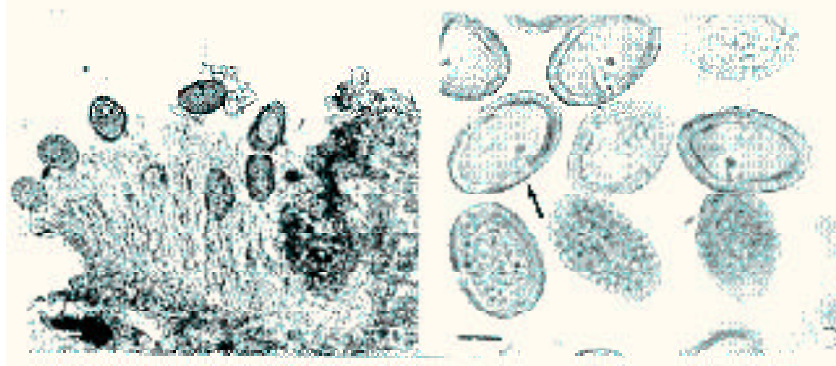

FIG. 4 - Uromyces foveolatus sobre Bauhinia acuruana. A e B - Corte de soros mistos contendo teliósporos e uredinióporos, subepidérmicos, anfígenos vistos ao MO C - Soro misto ao MO, mostrando urediniósporos e teliósporos. D - Urediniósporos com poros germinativos (seta) e teliósporos reticulados e alveolados vistos ao MO. Barras: A, B e C $=30 \mu \mathrm{m} ; \mathrm{D}=10 \mu \mathrm{m}$.
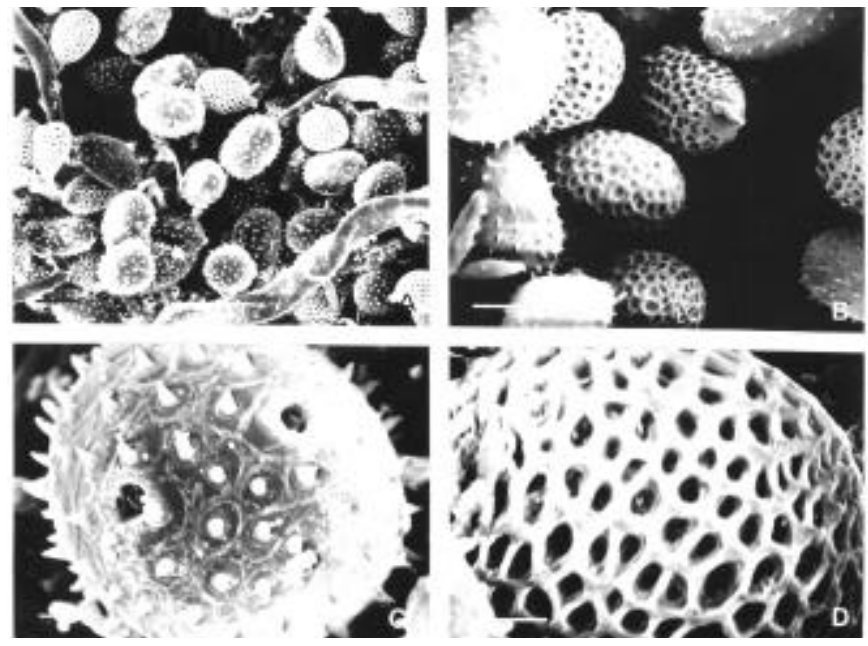

FIG. 5 - Uromyces foveolatus sobre Bauhinia acuruana ao MEV. A Urediniósporos equinulados e teliósporos reticulados, alveolados. B - Detalhe de superfície de urediniósporos e teliósporos. C Urediniósporos com equinulações cônicas cercadas por um retículo de nervuras leves. D - Teliósporo reticulado com alvéolos profundos. Barras: $\mathrm{A}=20 \mu \mathrm{m} ; \mathrm{B}=10 \mu \mathrm{m} ; \mathrm{C}$ e $\mathrm{D}=5 \mu \mathrm{m}$.

\section{5 - B e D).}

Espécimen examinado: em folhas vivas de Bauhinia acuruana Moric. var. nitida Benth.: Campo Grande, MS, 22 jul. 1993, leg. J.C. Dianese 1041, UB (col. micol.) 4409.

Uromyces foveolatus caracteriza-se por apresentar urédios sem paráfises, urediniósporos grandes, com quatro poros germinativos, raramente cinco. Os télios são mistos, pretos com teliósporos amplamente reticulados, paredes bilaminadas, com ambas as camadas espessas, formando papila com até $7 \mu \mathrm{m}$ de altura e os pedicelos com bases rugosas (Almeida, 1975). Estas características prestam-se para separar U. foveolatus de outras espécies de Uromyces em Bauhinia e são observadas com facilidade em microscópio ótico. Entre as espécies com teliósporos reticulados e com paredes bilaminadas encontram-se somente duas espécies. Uma delas é $U$. bauhiniae, que difere de U. foveolatus, por apresentar urediniósporos com até seis poros germinativos, teliósporos menores, com paredes mais finas e sem formar papila, porém com pedicelos longos até $60 \mu \mathrm{m}$ de comprimento e sem rugosidade na base. Portanto, o material estudado foi criteriosamente identificado e descrito como sendo $U$. foveolatus.

\section{Uromyces goyazensis P. Henn. Hedwigia 34:89. 1895.}

Espermogônios, écios e urédios não-vistos. Télios marrom-escuros, 0,3 - 0,5 cm até $2 \mathrm{~cm}$ de extensão em ramos, brotos, pecíolos (Figura 6 - A - C). Teliósporos marrom-escuros, obovóides a elipsóides, (20-) 24 (-30) x (14-) 19 (-23) $\mu \mathrm{m}$, reticulados, alveolados; paredes bilaminadas 1,5 - $2 \mu \mathrm{m}$ de espessura na porção lateral e 2 - $3 \mu \mathrm{m}$ no ápice espessado; um poro germinativo apical, alvéolos rasos, 0,5 - 1,0 $\mu \mathrm{m}$ de diâmetro, pedicelados. Pedicelos hialinos finos, longos, até $50 \mu \mathrm{m}$ de comprimento, quebrando-se próximo à base do esporo (Figura 6 - D, E e F). 
Espécies de Uromyces em leguminosas do cerrado com descrição...

Espécimes examinados: em folhas vivas de Bauhinia dumosa Benth. var. viscidula (Harms.) Vaz \& Marquete (=B. viscidula Harms.): Jardim Botânico de Brasília, DF, 14 mar. 1993, leg. J.C. Dianese 767, UB (col. micol.) 3596; Reserva Ecológica das Águas Emendadas, Planaltina, DF, 13 jun. 1995, leg. M. Sanchez 902, UB (col. micol.) 8756; Mata do Pitoco, Reserva Ecológica do IBGE, DF, 20 nov. 1995, leg. D.V. Rezende 22, UB (col. micol.) 10612.

Somente a fase teliomórfica de U. goyazensis foi descrita (Hennings, 1895; Viégas, 1945; Almeida, 1975). Entre os Uredinales afetando Bauhinia spp. com espermogônios, écios e urédios não-conhecidos e com teliósporos reticulados, estão apenas $U$. goyazensis e $U$. anthemophilus. Entretanto, os teliósporos de $U$. anthemophilus são menores, 18 - 25 x 18 - 22 $\mu \mathrm{m}$, quando comparados com os de $U$. goyazensis, além de serem ovóides, com paredes espessas, 3 - 3,5 $\mu \mathrm{m}$ de espessura dos lados, e arredondados nos ápices, alveolados, com alvéolos profundos e largos. Além disto, U. anthemophilus ocorre apenas em flores sem causar galhas sobre B. longifolia.Assim, conclui-se que o material examinado era somente $U$. goyazensis.

5. Uromyces viegasii Almeida. In: Fitop. Bras. 2:55. 1977.

Urédios e écios não-vistos. Espermogônios grupo V, tipo 4 , medindo $143 \mu \mathrm{m}$ de profundidade, $68 \mu \mathrm{m}$ de diâmetro na base e $70 \mu \mathrm{m}$ no topo, epífilos (Figura 7 - A e B). Télios marrom-
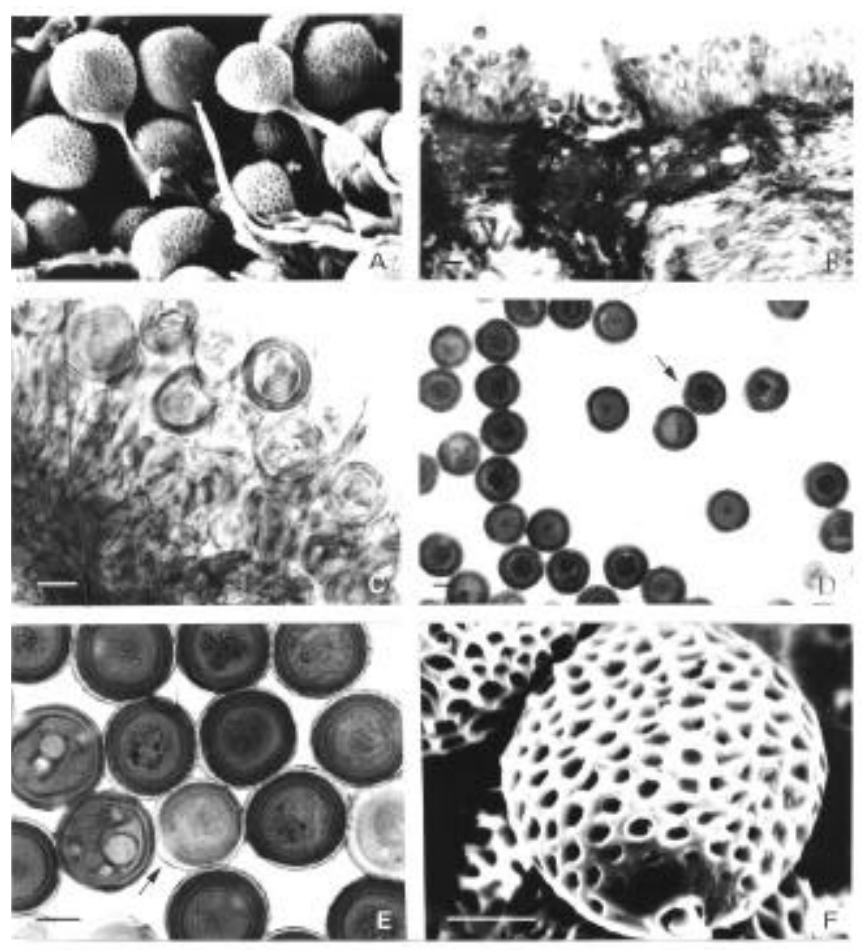

FIG. 6 - Uromyces goyazensis sobre Bauhinia dumosa. A - Conjunto de teliósporos pedicelados vistos ao MEV. B e C - Cortes de télios vistos ao MO. D e E - Teliósporos vistos ao MO, mostrando paredes espessas, bilaminadas, onduladas, formando pequenas papilas (seta). F - Teliósporo reticulado com alvéolos de 0,5 a 1,0 $\mu \mathrm{m}$ de diâmetro visto ao MEV. Barras: A, C, D e $E=10 \mu \mathrm{m} ; \mathrm{B}=30 \mu \mathrm{m} ; \mathrm{F}=5 \mu \mathrm{m}$. claros, anfígenos, (2-) 3 (-4) x (1-) 2 (-5) mm, dispersos ou em grupos, às vezes em círculos ao redor de espermogônios subepidérmicos, irrompentes, rodeados por halos amarelos (Figura 7 - C). Teliósporos (19-) 20 (-24) x (17-) 19 (-21) $\mu \mathrm{m}$, globóides a elipsóides, papilados; paredes douradas, 1,5 - 2,5 $\mu \mathrm{m}$ nos lados e 2 - $3 \mu \mathrm{m}$ nos ápices, reticuladas, alveoladas; alvéolos 2 - 2,5 $\mu \mathrm{m}$, raramente até $3 \mu \mathrm{m}$ de diâmetro. Pedicelos hialinos, des cíduos, 10 - $15 \mu \mathrm{m}$ de comprimento (Figura 7 - D, E e F).

Espécimes examinados: em folhas vivas de Bauhinia forficata L.: $\mathrm{km} 18$ da rodovia Mineiros em direção ao Parque Nacional das Emas, margem direita junto à placa EMAUS, Mineiros, GO, 12 abr. 1997, leg. M. Sanchez 3215, UB (col. micol.) 14318; Chapada dos Guimarães, Rodovia em direção a Brasilândia e Campo Verde, MT, 21 maio 1995, leg. M. Sanchez 1785, UB (col. micol.) 8756; Fazenda Botelho Puntel, Paracatu, MG, 12 maio 1994, leg. J. C. Dianese 1017, UB (col. micol.) 4586.

Para Almeida $(1975,1977)$ esta espécie é muito próxima de $U$. floralis, ocorrendo em $B$. hiemalis e $U$. anthemophilus em B. longifolia, mas difere por apresentar alvéolos largos nas paredes dos teliósporos. Além disso, U. anthemophilus possui teliósporos sem papilas, com paredes de 3 - 3,5 $\mu$ m de espessura,
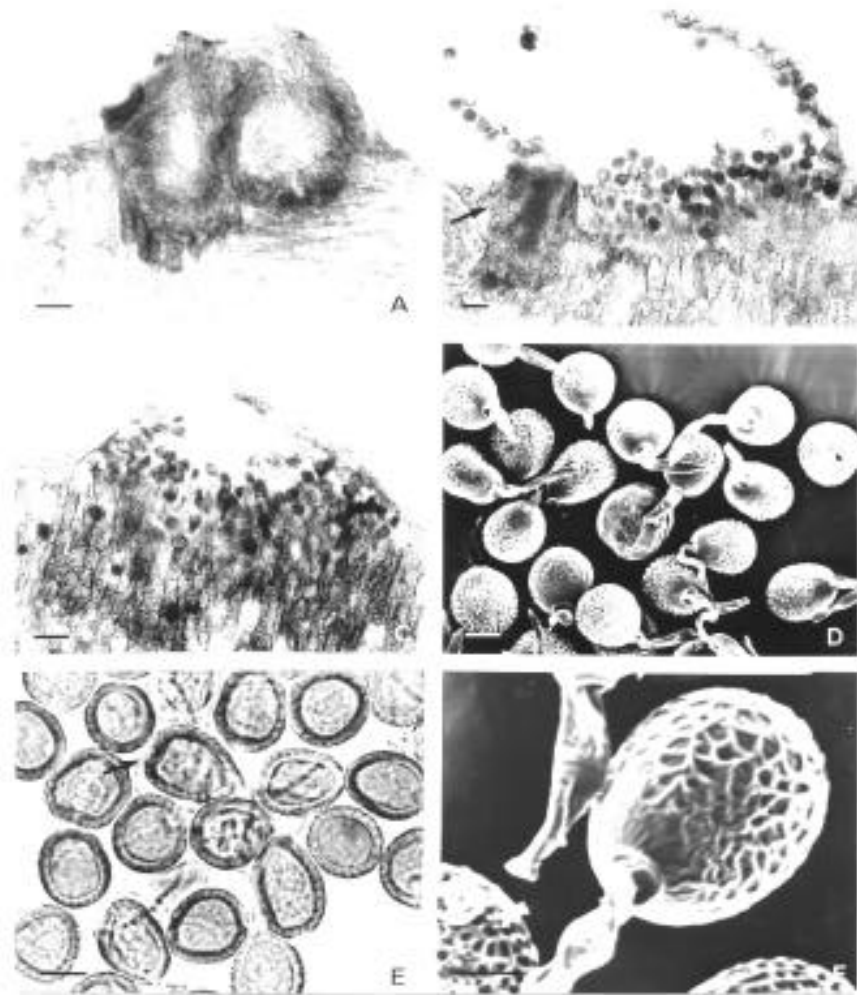

FIG. 7 - Uromyces viegasii sobre Bauhinia forficata. A - Par de espermogônios epífilos, do grupo V, tipo 4, vistos ao MO. B Corte de espermogônio (seta) associado ao télio, subepidérmico epífilo, visto ao MO. C - Corte de télio subepidérmico visto ao MO. D - Teliósporos reticulados mostrando alvéolos largos e rasos. E - Teliósporos reticulados vistos ao MO, mostrando paredes bilaminadas espessas e papilas pequenas. F - Detalhe de teliósporo pedicelado enfatizando seus alvéolos rasos e superfície lisa em torno da inserção do pedicelo. Barras: A, B, D e E $=10 \mu \mathrm{m}$; B e C $=30 \mu \mathrm{m} ; \mathrm{F}=5 \mu \mathrm{m}$. 
enquanto que os teliósporos de $U$. viegasii têm paredes mais finas $(1,5-2 \mu \mathrm{m})$ e papilas proeminentes. Outra diferença está nos soros marrons rodeados por halos amarelos, característicos de $U$. viegasii, ausentes em todas as outras espécies de Uromyces encontradas em Bauhinia. No caso presente, as características nos espécimes estudados mostraram que se trata de U. viegasii.

\section{Uromyces galactiae Rezende \& Dianese, sp. nov.}

Spermogonia et aecia ignota. Sori mixti urediniosporae et teliosporae continens (20-) 33 (-38) x 19 (-25) $\mu \mathrm{m}$, hypophyli, subepidermales vel erumpentes, aureo brunnei, pulveracei, minuti, paraphysati. Paraphyses tenues, hymeniales, apicibus clavatis, 25-30 $\mu \mathrm{m}$ longa x 1,5-2,5 $\mu \mathrm{m}$ lata. Urediniosporae (23-) $25(-27) \times(21-) 23(-25) \mu \mathrm{m}$ rhomboideae, obovoideae vel globosae, echinulatae; poris germinationis 2, subequatorialis; parietes $(1-1,5) \mu \mathrm{m}$ plerunque $1,5 \mu \mathrm{m}$ crassae. Teliosporae (25-) $35(-41) \times(9-) 12(-17) \mu \mathrm{m}$, laeves, rarae, oblongae, elipsoideae vel fusiformes, hialinae, pedicellatae; pedicellis deciduis; parietes laterales $0,5-1.0 \mu \mathrm{m}$ crassae; parietes apicales $1,5-4$ $\mu \mathrm{m}$ crassae.

Holotypus: in follis vivis Galactiae peduncularis (Benth.) Taub., Estação Ecológica das Águas Emendadas, Planaltina, Distrito Federal, Brasil, 27 fev. 1997, leg. M. Sanchez 2359, UB (col. micol.) 13573.

Outros espécimes examinados: em folhas vivas de Clitoria laurifolia Poir (=Neurocarpum cajanifolium Presl.), (=Clitoria cajanifolia (Presl.) Benth.): praia de Itamambuca, Ubatuba, São Paulo, SP, 5 jan. 1992, leg. J.C. Dianese 578, UB (col. micol.) 2327; praia de Itamambuca, Ubatuba, São Paulo, SP, 04 ago. 1997, leg. J.C. Dianese 3274, UB (col. micol.) 14824; Fazenda Bolandeira, Município de Una, BA, perto da entrada da ilha Comandatuba, BA, 26 ago. 1995, leg. M. Sanchez 1168, UB (col. micol.) 9891.

Espermogônios e écios não-vistos. Soros mistos contendo urediniósporos e teliósporos, hipófilos, subepidérmicos, irrompentes, marrom-dourados, pequenos, (20-) 33 (-38) $\mathrm{x}(13-) 19(-25) \mu \mathrm{m}$, pulverulentos, parafisados. Paráfises finas, clavadas nos ápices, 25 - $30 \mu \mathrm{m}$ de comprimento e 1,5 - 2,4 $\mu \mathrm{m}$ de diâmetro, himeniais (Figura 8 - A e B). Urediniósporos rombóides, obovóides a globóides (23-) 25 (-27) x (21-) 23 (-25) $\mu \mathrm{m}$; equinulados, mas lisos ao redor dos poros germinativos; dois poros germinativos, subequatoriais; paredes 1,0 - 1,5 $\mu \mathrm{m}$ de espessura, maioria 1,5 $\mu \mathrm{m}$ (Figura 8 - C, D e E e F). Teliósporos raros, oblongos, elipsóides ou fusiformes (25-) $35(-41)$ x (9-) $12(-17) \mu \mathrm{m}$, lisos, hialinos; paredes 0,5 - $1 \mu \mathrm{m} \mathrm{de}$ espessura na porção lateral, 1,5 - 4,0 $\mu \mathrm{m}$ nos ápices pedicelados; pedicelos hialinos, decíduos (Figura 8 - G e H).

Para se discutir $U$. galactiae sp. nov. levou-se em conta observações feitas para $U$. neurocarpi Diet. sobre C . laurifolia Benth., amplamente estudada recentemente por Rezende (1999).

A espécie tipo de $U$. neurocarpi, foi coletada por Lhotsky no Estado da Bahia e descrita por Dietel (1895), ocorrendo em C. laurifolia Benth. Viégas (1945) descreveu o mesmo fungo em $C$. rubiginosa Jussieu ex. Fr. em Minas Gerais e Almeida (1975) o redescreveu com base em seu holótipo. Os écios e eciósporos no material ora estudado são anfígenos e maiores do que os urédios e télios, porém Almeida (1975) referese aos espermogônios como epífilos e aos écios hipófilos.

Os teliósporos de $U$. neurocarpi são menores e lisos e não com verrugas formando linhas e raramente lisos como descrito por Almeida (1975). Os pedicelos dos teliósporos são longos, hialinos e medindo até $50 \mu \mathrm{m}$ de comprimento por 2-3 $\mu \mathrm{m}$ de diâmetro, não sendo curtos e decíduos como descrito por Almeida (1975), ao examinar o holótipo da espécie.

Espermogônios, écios e eciósporos não foram encontrados em todos os materiais estudados de G. peduncularis. Os urédios parafisados, são hipófilos, subepidérmicos, tornando-se irrompentes e são menores do que os de $U$. neurocarpi. Os urediniósporos apresentam-se muito semelhantes aos de U.neurocarpi, porém em média apresentam-se maiores e mais densamente equinulados, mas com equinu-
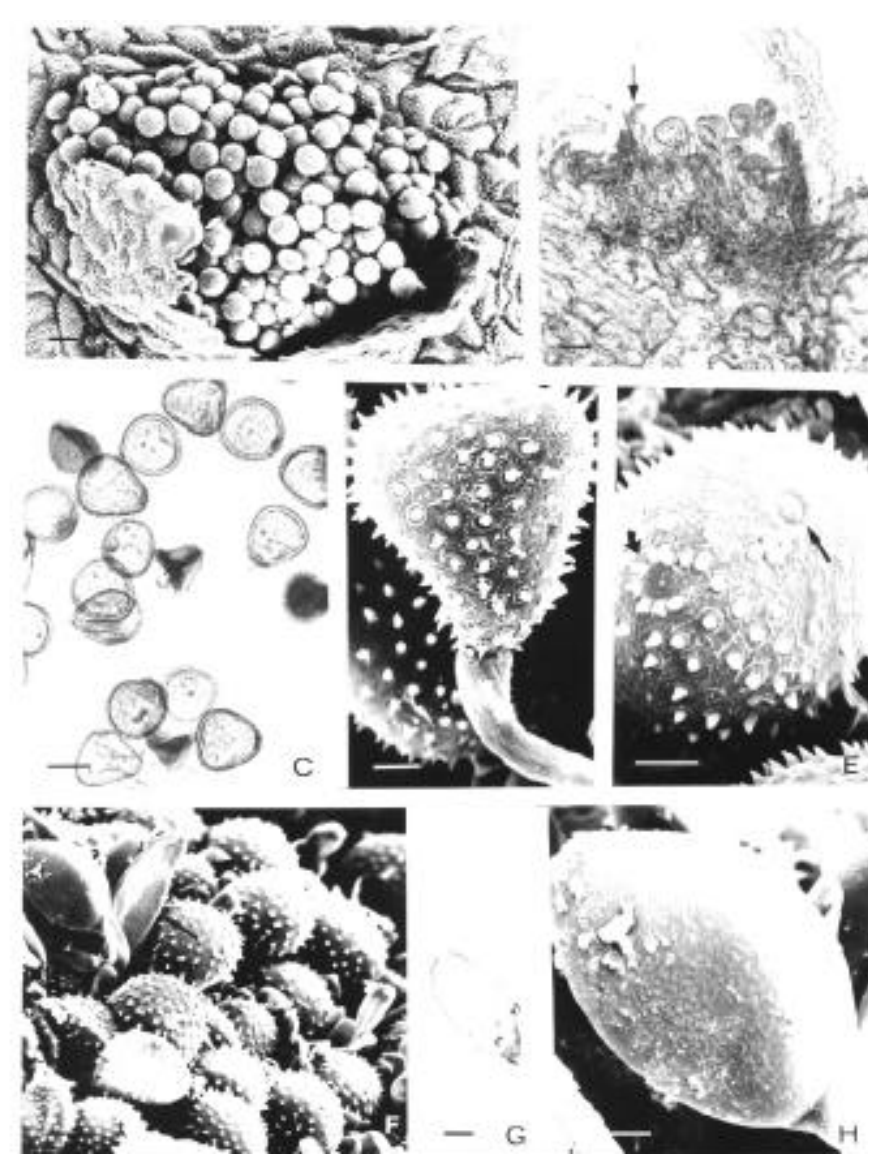

FIG. 8 - Uromyces galactiae sp. nov. A - Urédio subepidérmico visto ao MEV. B - Corte de urédio ao MO, mostrando urediniósporos e paráfises (seta). C - Urediniósporos ovóides a romboidais com poros germinativos equatoriais, vistos ao MO. D e E - Detalhes de urediniósporos com halos ao redor das equinulações, vistos ao MEV, mostrando inclusive um poro germinativo (seta) e uma coroa de equinulações basais junto a ponto de inserção do pedicelo (seta). F Soro misto ao MEV contendo principalmente urediniósporos e alguns teliósporos ressecados e murchos (seta) e paráfises himeniais. G e H - Teliósporos lisos vistos respectivamente ao MO e MEV. Barras: A, $\mathrm{B}$ e $\mathrm{C}=20 \mu \mathrm{m} ; \mathrm{D}, \mathrm{E}, \mathrm{G}$ e $\mathrm{H}=5 \mu \mathrm{m} ; \mathrm{F}=10 \mu \mathrm{m}$. 
Espécies de Uromyces em leguminosas do cerrado com descrição...

lações bem mais delicadas, quando comparadas às de $U$. neurocarpi. Os urediniósporos têm dois poros germinativos subequatoriais, também sem equinulações ao redor deles, diferenciando, entretanto, de U. neurocarpi que apresenta dois poros germinativos equatoriais e um apical facilmente vistos em MEV. Os télios são hipófilos, mistos, quase sempre com poucos teliósporos, enquanto que em $U$. neurocarpi, estes são anfígenos, com maioria hipófila e maiores.

Os teliósporos de $U$. galactiae têm em comum com os de U. neurocarpi a característica de germinação sem dormência, serem hialinos, lisos, oblongos, elipsóides ou fusiformes, e as paredes laterais mediram 0,5-1 $\mu \mathrm{m}$ de espessura. Porém, os teliósporos de $U$. galactiae mostraram-se com ápices medindo de 1,5 a 4,0 $\mu \mathrm{m}$, maiores do que os de $U$. neurocarpi com, no máximo, $3 \mu \mathrm{m}$ de espessura. Os teliósporos de $U$. galactiae mediram em média $35 \times 12 \mu \mathrm{m}$ e os de $U$. neurocarpi, $30 \times 15 \mu \mathrm{m}$.

\section{REFERÊNCIAS BIBLIOGRÁFICAS}

ALMEIDA, R.T. A taxonomic analysis of the species of Uromyces on legumes in Brazil. (Ph. D, Dissertation) The University of Arizona. 1975.

ALMEIDA, R.T. Duas novas espécies de Uromyces sobre leguminosas do gênero Bauhinia no Brasil. Fitopatologia Brasileira 2:55-57. 1977.

BRUZESSE, E. \& HASAN, S. A whole leaf clearing and staining technique for host specificity studies of rust fungi. Plant Pathology 32:335-338. 1983.

DIETEL, P. Einige newe exotische Pilze. Hedwigia 34:291-292. 1895. HENNEN, J.F.; HENNEN, M.M. \& FIGUEIREDO, M.B. Índice das ferrugens (Uredinales) do Brasil. Arquivo do Instituto Biológico de São Paulo (supl. 1). 1982.

HENNINGS, P. Fungi goyasenses. Hedwigia 34:88-116. 1895.

REZENDE, D. V. Taxonomia de Uredinales em plantas da família Leguminosae do cerrado brasileiro. (Tese de Doutorado) Universidade de Brasília. Brasilia. 1999.

VESTERGREN, T. Monographie des auf der Leguminosen-Gattung Bauhinia vorkommenden Uromyces - Arten. Ark. Bot. 4:1-34. 1905.

VIÉGAS, A. P. Alguns fungos do Brasil IV - Uredinales. Bragantia 5:1-144. 1945. 